\title{
A review and analysis of content based image retrieval system
}

\author{
Savita Chauhan* \\ Technocrats Institute of Technology (Excellence), Bhopal
}

C2017ACCENTS

\begin{abstract}
Content based image retrieval (CBIR) is an emerging trend in the era of efficient image retrieval in today's world. It is a searching technique which allows the retrieval based on the content. In this procedure the searching is entirely based on the similarity of the index value obtained. The CBIR area is more diverse as it is used in different domains like medical image diagnosis, classification and face recognition etc. The objective of this paper is to analyzing and discussing the latest developments in this field. Comparison contains the methodological analysis along with the prospective advantages and disadvantages. The results discussion of the previous methodologies has been analyzed also. It provides the gap identifications and future challenges which can be redirected in the near future. This discussion is based on the retrieval techniques which used the color, texture, shape and dominant color in the image retrieval.
\end{abstract}

\section{Keywords}

CBIR, Content retrieval, Colour, Shape, Texture and Dominant color.

\section{Introduction}

Investigate on content based image retrieval and similarity matching has expanded monstrous in the most recent decade. A significant measure of examination work has been done on Image Retrieval by various investigators, reaching out in both significance and extensiveness [1-5]. The term content based image retrieval (CBIR) seems to have begun with the work of Kato [6] for the modified recuperation of the photos from a database, in perspective of the shading and shape display. Starting now and into the foreseeable future, the term has by and large been used to depict the technique of recuperating pined for pictures from an extensive social occasion of database, on the commence of picture components (color, texture and shape). The calculations, techniques and the framework utilized that are used, begin from the fields, for instance, estimations, plan affirmation, information get ready, and data mining and $\mathrm{PC}$ vision.

Image data provides the information separated from pictures through electronic or reproduced estimations [5]. CBIR frameworks are correspondingly working with a similar lay [6]. An area vector is expelled from every photograph in the database and the strategy of all highlight vectors is enclosed as a database record [7].

\footnotetext{
*Author for correspondence
}

At the time, a substitution vector is expelled from the sales picture other than; it is empowered against the segment vectors in the record [8-16].

Basically, most CBIR systems work similarly: a component vector is removed from each photo in the database and the plan of all highlight vectors is created as a database record [17]. At request time, a part vector is removed from the question picture what's more; it is facilitated against the component vectors in the record. The fundamental difference between the distinctive systems lies in the parts that they remove and in the counts that are utilized to take a gander at highlight vectors [18]. The shading parts are the most by and large used visual components in picture recuperation in light of the way that they are less requesting to isolate differentiated and surface and shape information. Shading highlight is reasonably effective to establishment multifaceted design and free of picture size and presentation. Quantifiably, it shows the joint probability of the powers of the three shading channels.

Texture is a fundamental component of ordinary pictures. Mixes of techniques have been made for measuring structure likeness. Most techniques rely on upon taking a gander at estimations of what are known as second-demand estimations figured from request and set away pictures [19]. These schedules figure measures of picture surface, for instance, the level of distinction, coarseness, directionality and 
consistency [20-21]; or periodicity, directionality and mediation [22]. Elective methods for texture examination for picture recuperation consolidate the usage of Gabor channels [23] and fractals [24].

The two main objectives of this paper are to study and analyses the aspects of the methods used and the gap identification.

\section{Related works}

In 2012, Das et al. [25] suggested a CBIR system that can apply on different feature of images. To focus shading highlights from a photo, one of the standard ways i.e. shading histogram was used as a piece of $\mathrm{YCbCr}$ and HSV shading space. Daubechies' wavelet change and Symtel's wavelet change were performed to isolate the surface component of a photo. They have proposed a shading based recuperation structure in which fluffy abilities was being used for the fragment of the HSV shading space and wavelet change of the fuzzified new picture. To extend viability of the system finally a picture recuperation strategy was proposed using curvelet change of a picture, which allows focusing more exact surface component for picture recuperation. The outcomes bolster the curvelet techniques in contrast with alternate strategies.

In 2012, Chaudhari et al. [26] recommended that the CBIR utilizes the visual properties of a picture, for example, shading, shape, surface, and spatial format to speak to and file the picture. They proposed a calculation which is the hybridization of various productive calculations to enhance the exactness and execution of recovery. The precision of shading histogram based planning can be extended by using color coherence vector (CCV) for dynamic refinement. The pace of shape based recuperation can be overhauled by considering evaluated shape rather than the distinct shape. Despite this a blend of shading and shape based recuperation is similarly included to upgrade the precision of the result.

In 2013, Bhagat et al. [27] proposed that the execution of an electronic extensible outline that is easily crucial with applications written in different tongues and linkable with different data sources. This printed material oversees making building which is expandable and specific; its client-server functionalities permit easily developing web applications that can be run using any Internet program without similitude issues as to stage, program and working structure presented. They display the use of CBIR framework that using assorted procedures for shading, surface and shape examination. The basic target is to consider the unmistakable methodologies for picture mapping.

In 2013, Mathur et al. [17] CBIR is a compelling technique for recovering pictures from huge picture assets. CBIR is a framework in which pictures are documented by removing their low level parts like, shading, surface, shape, and spatial region, et cetera. Intense and profitable component extraction instruments are required to upgrade existing CBIR execution. This paper shows a novel philosophy of CBIR system in which higher recuperation profitability is proficient by joining the information of picture components shading, shape and surface. The shading highlight is removed using shading histogram for picture impedes, for shape highlight Canny edge acknowledgment figuring is used and the HSB extraction as a piece of pieces is used for surface component extraction. The rundown of capacities of the pictures are differentiated and the rundown of abilities of each photo in the database. The examinations show that the mix of different components recuperation gives best recuperation comes about over another strategy used.

In 2014, Wan et al. [28] recommended that the learning portrayals and comparability measures are critical for CBIR framework. They have proposed that semantic crevice issue which can be exists in the low-level picture pixels which are just caught by machines and abnormal state semantic ideas saw by human. Among various methodologies, machine learning has been adequately inspected as a possible making a beeline for associate the semantic vacuum in the whole deal. Impelled by late achievements of significant learning systems for PC vision and distinctive applications, they attempt to address an open issue: if significant learning is a craving for traverse the semantic vacuum in CBIR and the measure of upgrades in CBIR errands can be refined by exploring the bleeding edge significant learning procedures for learning highlight portrayals and closeness measures. In CBIR assignments with an expansive game plan of observational reviews by taking a gander from an optimistic standpoint in class significant learning technique (Convolutional Neural Networks) for CBIR errands under contrasted settings. Their exploratory reviews recommended promising outcomes.

In 2014, Choudhary et al. [29] proposed a substance based picture recuperation facilitated technique which isolates both the (shading) and (surface) part. 
To isolate the shading part, shading minute $(\mathrm{CM})$ is used on shading pictures and to remove the surface component, neighborhood twofold case (LBP) is performed on the grayscale picture. By then both shading and organization highlight of picture are joined to shape a lone part vector. Finally likeness planning is performed by Euclidian partition which contrasts highlight vector of database pictures and question pictures. LBP mainly used for face affirmation. Regardless, we will use LBP for basic pictures. This joined procedure gives correct, profitable, less astounding recuperation structure.

In 2014, Jenni et al. [30] proposed a proficient strategy called pre-preparing picture database utilizing k-implies bunching and hereditary calculation. This system utilizes a couple of segments of the photo, for instance, shading, edge thickness, boolean edge thickness and histogram information as the data of recuperation. Besides, a couple execution estimations, for instance, confuse cross section, precision outline and F-measures, have in addition been used as a piece of measuring the accuracy of the proposed framework. The investigation comes about exhibit that the batching flawlessness in extra than a substantial segment of the clusters has been more than 90 display perfection.

In 2015, Alzu'bi et al. [31] recommended that the multimedia contents complexity in nature is expanding predominantly in the current computerized world. So this creates the need of exceptionally compelling recovery frameworks. They have displayed their review in the field of CBIR framework. They exhibited and highlighted the review identified with the photo pre-processing, highlight extraction and ordering, system learning, benchmarking datasets, similarity organizing, criticalness feedback, execution evaluation, and portrayal.

\section{Problem findings}

Based on the literature discussed the following problem findings have been recognized:

1. Combination of different content based image retrieval techniques along with dominant color extraction is missing in previous work.

2. Retrieving the texture and edges correctly is not so easy.

3. Many CBIR strategies confront execution debasement if there should arise an occurrence of inward locale, intra area and picture determination on account of space particular nature.

4. Dominant components are less utilized however it is important in highlight determination and better recovery.

5. Image differing qualities and semantic crevice is likewise a noteworthy issue in proficient recovery.

6. Different research work missing edge location and locale arrangement. So the measurement edges are not proficiently used.

7. Boundary discovery and relationships in the pixels are not properly discovered.

\section{Analysis}

Method based comparison is shown in Table 1. The below comparison discussed the method used in previous research work along with the advantages of the algorithms. It also highlights the limitations of the work so that it can be further extended in the direction suggested.

Table 1 Method based comparisons

\begin{tabular}{|c|c|c|c|c|}
\hline S.NO & Reference & Method & Advantages & Limitation \\
\hline 1 & [32] & $\begin{array}{l}\text { They have reviewed different CBIR } \\
\text { algorithms based on colour, texture and } \\
\text { shape features, and how the image features } \\
\text { can be extracted from the compressed } \\
\text { domain. }\end{array}$ & $\begin{array}{l}\text { It provides the survey of without } \\
\text { decompressing the images. }\end{array}$ & $\begin{array}{l}\text { The } \\
\text { implementations } \\
\text { part and the } \\
\text { applicability are } \\
\text { missing. }\end{array}$ \\
\hline 2 & {$[33]$} & $\begin{array}{l}\text { They proposed novel system architecture } \\
\text { for CBIR system which include content- } \\
\text { based image and color analysis with the } \\
\text { data mining capabilities. They have } \\
\text { proposed segmentation and grid module, } \\
\text { feature extraction module, K-means and k- } \\
\text { nearest neighbor clustering algorithms and } \\
\text { bring in the neighborhood module to build } \\
\text { the CBIR system. }\end{array}$ & $\begin{array}{l}\text { The query stage can be optimized in } \\
\text { the image retrieval steps. }\end{array}$ & $\begin{array}{l}\text { System optimization } \\
\text { issues have been } \\
\text { suggested by the } \\
\text { authors. }\end{array}$ \\
\hline 3 & [34] & $\begin{array}{l}\text { They have presented an algorithm for } \\
\text { retrieving images } \\
\text { where the }\end{array}$ & $\begin{array}{l}\text { It is intriguing to examine whether } \\
\text { the proposed shape portrayal is }\end{array}$ & $\begin{array}{l}\text { Area wise } \\
\text { application and their }\end{array}$ \\
\hline
\end{tabular}




\begin{tabular}{lllll}
\hline S.NO & Reference & Method & Advantages & Limitation \\
\hline & $\begin{array}{l}\text { engineering/computer-aided design (CAD) } \\
\text { models have been considered as the }\end{array}$ & valuable in other application areas, & applicability is a \\
& $\begin{array}{l}\text { databases. The calculation employments } \\
\text { che protein looks in sub-atomic science. }\end{array}$ & phallenging issue.
\end{tabular}

the shape data in a picture alongside its 3D data. A direct guess strategy that can catch the profundity data utilizing shape from shading has been utilized. Recovery of items is then done utilizing a likeness measure that joins shape and the profundity data. Plotted exactness/review bends demonstrate that this technique is extremely successful for a building database.

They propose a content-based image retrieval method which combines color and texture features. To enhance the separating force of shading ordering systems, we encode an insignificant measure of spatial data in the shading record. As its shading highlights, a picture is partitioned on a level plane into three equivalent noncovering locales. From every district in the picture, we extricate the initial three snapshots of the shading dispersion, from each shading divert and store them in the list i.e., for a HSV shading space, store 27 drifting point numbers for every picture. They have presented a Bayesian framework for content-based image retrieval. It models the distribution of color and texture features within sets of related images. aspects of CBIR along with the features for image Retrieval like color, texture and shape.

The color histogram for an picture is developed by quantizing the hues inside the picture and tallying the quantity of pixels of each shading. The element vector of a
The results have been improved by combining color moments and texture

features based on global features approach.

Despite the fact that

the Bayesian score depends on processing minor probabilities, which incorporate over model parameters, in the instance of meager paired information the score diminishes to a solitary framework vector duplication and is accordingly greatly effective to process.

They have suggested several implications in content-based image retrieval for effective indexing and fast searching of images based on visual features. Measurement diminishment and ordering plans are likewise talked about. For substance based picture recovery, client connection with the recovery framework is essential since adaptable development and alteration of questions must be gotten by including the client in the recovery strategy. At last Relevance input is examined which helps in enhancing the execution of a CBIR framework.

With a specific end goal to have comparative components of the pictures the framework code must be same for all Images in the
Dominant color can be used for the betterment.
Relevance feedback and specific image target have been suggested by the authors.

The implementations part and the applicability are missing.

Along with the feature vector properties some dominant constraints 


\begin{tabular}{|c|c|c|c|c|}
\hline S.NO & Reference & Method & Advantages & Limitation \\
\hline & & $\begin{array}{l}\text { picture can be gotten from the histograms } \\
\text { of its shading segments lastly can set the } \\
\text { quantity of canisters in the shading } \\
\text { histogram to get the component vector of } \\
\text { coveted size. In this way the network code } \\
\text { of a picture is acquired through the } \\
\text { quantization of the highlight vector got } \\
\text { from the histogram of the coveted shading } \\
\text { part of the picture. }\end{array}$ & network. & $\begin{array}{l}\text { can be applied for } \\
\text { the better results. }\end{array}$ \\
\hline 8 & [39] & $\begin{array}{l}\text { They have forwarded the non-equal } \\
\text { interval quantization scheme that makes the } \\
\text { statement of the picture data to be more } \\
\text { sensible. }\end{array}$ & $\begin{array}{l}\text { In highlight portrayal stage, they } \\
\text { have utilized the element } \\
\text { combination component that makes } \\
\text { the shading also, shape data } \\
\text { combine and show signs of } \\
\text { improvement results. The } \\
\text { investigation comes about exhibit } \\
\text { that the proposed strategy more } \\
\text { productive and have a high recovery } \\
\text { execution. }\end{array}$ & $\begin{array}{l}\text { Area wise } \\
\text { application and their } \\
\text { applicability is a } \\
\text { challenging issue. }\end{array}$ \\
\hline
\end{tabular}

The result based discussion is shown in Table 2. It suggests the result discussion based on the method and the achieved results. It also discussed the results obtaining methods and achieving parameters to discuss it in the relevance of the methodology. It also shows the discussion based on the results impact.

Table 2 Analysis

\begin{tabular}{|c|c|c|c|}
\hline S.NO & Reference & Method & Result \\
\hline 1 & [40] & $\begin{array}{l}\text { Multi-modular re-positioning has been utilized to } \\
\text { Integrate learning of significance score, weights of }\end{array}$ & $\begin{array}{l}\text { More hearty than utilizing each } \\
\text { Singular methodology and better }\end{array}$ \\
\hline & & $\begin{array}{l}\text { Methodology, separate lattice and its scaling into } \\
\text { brought together plan. }\end{array}$ & $\begin{array}{l}\text { Execution than existing } \\
\text { methodologies. }\end{array}$ \\
\hline 2 & [41] & $\begin{array}{l}\text { They have utilized roundabout re-positioning } \\
\text { technique. Recovered pictures are displayed as charts } \\
\text { in various component spaces like Random strolls, } \\
\text { Mutual support and Circular Re-positioning. }\end{array}$ & $\begin{array}{l}\text { Addresses the issue of multimodality } \\
\text { Interaction in visual inquiry by } \\
\text { shared fortification. Along these } \\
\text { lines, the execution of the feeble } \\
\text { Modality is additionally profited by } \\
\text { gaining from solid modalities. }\end{array}$ \\
\hline 3 & [42] & $\begin{array}{l}\text { They have exhibited Content Based Image Retrieval } \\
\text { as both on the web and disconnected. }\end{array}$ & $\begin{array}{l}\text { It is simple and quick to seek and } \\
\text { recover the pictures. In an } \\
\text { indistinguishable route from a future } \\
\text { work it should be possible for voice } \\
\text { recording and } \\
\text { voice looking. The pictures can be } \\
\text { recovered by both on the web and } \\
\text { disconnected in view of the inquiry } \\
\text { picture which enhances execution of } \\
\text { the CBIR framework }\end{array}$ \\
\hline 4 & [43] & $\begin{array}{l}\text { They have displayed ontologically controlled } \\
\text { IR technique in contrast with the traditional CBIR } \\
\text { working and demonstrates that the presentation of a } \\
\text { progressive structure enhances accuracy comes about } \\
\text { for the framework. }\end{array}$ & $\begin{array}{l}\text { Their outcome demonstrates that, } \\
\text { with the utilization of negligible } \\
\text { semantic data (a term related to every } \\
\text { photograph), the consequences of a } \\
\text { CBIR procedures are genuinely } \\
\text { progressed. }\end{array}$ \\
\hline 5 & [44] & $\begin{array}{l}\text { They have distinguished five noteworthy classes of } \\
\text { the best in class procedures in narrowing down the } \\
\text { 'semantic crevice': (1) utilizing object philosophy to } \\
\text { characterize abnormal state ideas; (2) utilizing } \\
\text { machine learning strategies to connect low level }\end{array}$ & $\begin{array}{l}\text { Spatial division is performed on this } \\
\text { class-outline can be seen as an } \\
\text { uncommon sort of surface structure. }\end{array}$ \\
\hline
\end{tabular}


Savita Chauhan

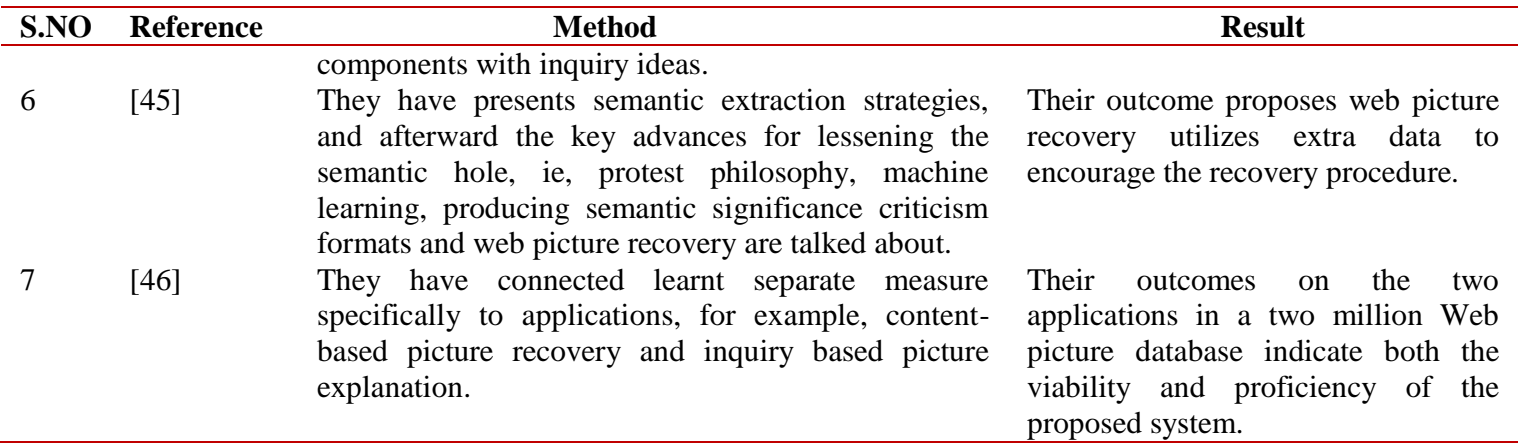

\section{Conclusion and future work}

In this paper a detail analysis based on the previous study and literature has been presented. Then methodical aspects have been analyzed. Different aspects have been analyzed and discussed with the aspects of challenges, advantages and problem statements. Based on the analysis following future work have been suggested.

1. Texture color and shape can be taken simultaneously for the better retrieval.

2. Dominant color based selection may improve the chances of better retrieval.

3. Specific image targets for all the conditions for the comparison from different methods.

\section{Acknowledgment}

None.

\section{Conflicts of interest}

The authors have no conflicts of interest to declare.

\section{References}

[1] Datta R, Joshi D, Li J, Wang JZ. Image retrieval: Ideas, influences, and trends of the new age. ACM Computing Surveys. 2008; 40(2):5.

[2] Liu Y, Zhang D, Lu G, Ma WY. A survey of contentbased image retrieval with high-level semantics. Pattern Recognition. 2007; 40(1):262-82.

[3] Prasanna MK, Rai SC. Image Processing AlgorithmsA Comprehensive Study. International Journal of Advanced Computer Research. 2014; 4(2):532-9.

[4] Anandan P, Sabeenian RS. Curvelet based image compression using support vector machine and core vector machine-a review. International Journal of Advanced Computer Research. 2014; 4(2):673-9.

[5] Ghosh P, Pandey A, Pati UC. Comparison of Different Feature Detection Techniques for Image Mosaicing. ACCENTS Transactions on Image Processing and Computer Vision.2015; 1(1):1-7.

[6] Kato T. Database architecture for content-based image retrieval. In SPIE/IS\&T 1992 symposium on electronic imaging: science and technology 1992 (pp. 112-3). International Society for Optics and Photonics.
[7] Flickner M, Sawhney H, Niblack W, Ashley J, Huang Q, Dom B, et al. Query by image and video content: the QBIC system.1995;28(9):23-32.

[8] Gupta A, Jain R. Visual information retrieval. Communications of the ACM. 1997; 40(5):70-9.

[9] Pentland A, Picard RW, Sclaroff S. Photobook: content-based manipulation of image databases. International Journal of Computer Vision. 1996; 18(3):233-54.

[10] Smith JR, Chang SF. VisualSEEk: a fully automated content-based image query system. In proceedings of the fourth ACM international conference on multimedia 1997 (pp. 87-98). ACM.

[11] Wang JZ, Wiederhold G, Firschein O, Xin Wei S. Content-based image indexing and searching using Daubechies' wavelets. International Journal on Digital Libraries. 1998; 1(4):311-28.

[12] Carson C, Belongie S, Greenspan H, Malik J. Blobworld: image segmentation using expectationmaximization and its application to image querying. IEEE Transactions on Pattern Analysis and Machine Intelligence. 2002; 24(8):1026-38.

[13] Wang JZ, Li J, Wiederhold G. SIMPLIcity: semanticssensitive integrated matching for picture libraries. IEEE Transactions on Pattern Analysis and Machine Intelligence. 2001; 23(9):947-63.

[14] Puviarasan N, Bhavani R. Retrieval of Images Using Weighted Features. International Journal of Advanced Computer Research. 2014; 4(1):60-5.

[15] Patidar D, Jain N, Nagariya B, Mishra M. Image classification by combining wavelet transform and neural network. International Journal of Advanced Computer Research. 2013; 3(4):106-10.

[16] Singh H, Kaur T. Novel method for edge detection for gray scale images using $\mathrm{VC}++$ environment. International Journal of Advanced Computer Research. 2013; 3(4):193-7.

[17] Mathur A, Mathur R. Content based image retrieval by multi features using image blocks. International Journal of Advanced Computer Research. 2013; $3(4): 251-5$.

[18] Viswa SS. Efficient retrieval of images for search engine by visual similarity and re ranking. International Journal of Advanced Computer Research. 2013; 3(2):47-52.

[19] Dubey A. Efficient content based image retrieval (CBIR) techniques: a survey. ACCENTS Transactions 
on Image Processing and Computer Vision. 2015; 1(1):28-32.

[20] Tamura H, Mori S, Yamawaki T. Textural features corresponding to visual perception. IEEE Transactions on Systems, Man, and Cybernetics. 1978; 8(6):460-73.

[21] Niblack CW, Barber R, Equitz W, Flickner MD, Glasman EH, Petkovic D, et al. QBIC project: querying images by content, using color, texture, and shape. In IS\&T/SPIE's symposium on electronic imaging: science and technology 1993 (pp. 173-87). International Society for Optics and Photonics.

[22] Liu F, Picard RW. Periodicity, directionality, and randomness: Wold features for image modeling and retrieval. IEEE Transactions on Pattern Analysis and Machine Intelligence. 1996; 18(7):722-33.

[23] Kaplan LM, Murenzi R, Namuduri KR. Fast texture database retrieval using extended fractal features. In photonics West'98 electronic imaging 1997 (pp. 16273). International Society for Optics and Photonics.

[24] Smith JR. Integrated spatial and feature image system: Retrieval, analysis and compression $[\mathrm{PhD}$ dissertation]. Columbia University, New York. 1997.

[25] Das S, Garg S, Sahoo G. Comparison of content based image retrieval systems using wavelet and curvelet transform. The International Journal of Multimedia \& its Applications. 2012; 4(4):137.

[26] Chaudhari R, Patil AM. Content based image retrieval using color and shape features. International Journal of Advanced Research in Electrical, Electronics and Instrumentation Engineering. 2012; 1(5):67-72.

[27] Bhagat AP, Atique M. Web based image retrieval system using color, texture and shape analysis: comparative analysis. International Journal of Advanced Computer Research. 2013; 3(3):58-66.

[28] Wan J, Wang D, Hoi SC, Wu P, Zhu J, Zhang Y, et al. Deep learning for content-based image retrieval: a comprehensive study. In proceedings of the $22 \mathrm{nd}$ ACM international conference on multimedia 2014 (pp. 157-66). ACM.

[29] Choudhary R, Raina N, Chaudhary N, Chauhan R, Goudar RH. An integrated approach to content based image retrieval. In international conference on advances in computing, communications and informatics 2014 (pp. 2404-10). IEEE.

[30] Jenni K, Mandala S. Pre-processing image database for efficient Content Based image retrieval. In international conference on advances in computing, communications and informatics 2014 (pp. 968-72). IEEE.

[31] Alzu'bi A, Amira A, Ramzan N. Semantic contentbased image retrieval: a comprehensive study. Journal of Visual Communication and Image Representation. 2015; 32:20-54.

[32] Schaefer G. An introduction to content-based image retrieval. In international conference on digital information management 2013 (pp. 4-6). IEEE.
[33] Chang RI, Lin SY, Ho JM, Fann CW, Wang YC. A novel content based image retrieval system using kmeans/knn with feature extraction. Computer Science and Information Systems. 2012; 9(4):1645-61.

[34] Jain A, Muthuganapathy R, Ramani K. Content-based image retrieval using shape and depth from an engineering database. Advances in Visual Computing. 2007:255-64.

[35] Huang ZC, Chan PP, Ng WW, Yeung DS. Contentbased image retrieval using color moment and Gabor texture feature. In international conference on machine learning and cybernetics 2010 (pp. 719-24). IEEE.

[36] Heller KA, Ghahramani Z. A simple Bayesian framework for content-based image retrieval. In computer society conference on computer vision and pattern recognition 2006 (pp. 2110-7). IEEE.

[37] Shete DS, Chavan MS. Content based image retrieval: Review. International Journal of Emerging Technology and Advanced Engineering. 2012; 2(9):85-90.

[38] Kumar AR, Saravanan D. Content based image retrieval using color histogram. International Journal of Computer Science and Information Technologies. 2013; 4:242-5.

[39] Gang H, Qinghe F, Xiaoxue Z, Jun K, Ming Z. Content-based image retrieval using texture structure histogram. In international conference on multimedia technology 2013 (1356-63). Atlantis Press.

[40] Wang M, Li H, Tao D, Lu K, Wu X. Multimodal graph-based reranking for web image search. IEEE Transactions on Image Processing. 2012; 21(11):464961.

[41] Yao T, Ngo CW, Mei T. Circular reranking for visual search. IEEE Transactions on Image Processing. 2013; 22(4):1644-55.

[42] Killikatt S, Kulkarni V, Bijjal M. Content based image retrieval by online and offline. International Journal of Advanced Research in Electronics and Instrumentation Engineering. 2013; 2(7):2761-8.

[43] Popescu A, Millet C, Moëllic PA. Ontology driven content based image retrieval. In proceedings of the 6th ACM international conference on Image and video retrieval 2007 (pp. 387-94). ACM.

[44] Kumar KV, Rao RR, Ramaiah VS, Kaka JR. Content based image retrieval system consume semantic gap. International Journal of Computer Science and Information Technologies. 2012; 3(5): 5231-5.

[45] Liu Y, Zhang D, Lu G, Ma WY. A survey of contentbased image retrieval with high-level semantics. Pattern Recognition. 2007; 40(1):262-82.

[46] Wang C, Zhang L, Zhang HJ. Learning to reduce the semantic gap in web image retrieval and annotation. In proceedings of the 31st annual international ACM SIGIR conference on research and development in information retrieval 2008 (pp. 355-62). ACM. 